\title{
Implementation of Road Safety Countermeasures in Four Cities to Reduce the Harmful Effects of Alcohol: A Progress Report
}

James C Fell ( $\sim$ fell-jim@norc.org )

NORC at the University of Chicago

Tom Achoki

ABIM: American Board of Internal Medicine

William DeJong

Tufts University School of Medicine

Deborah A. Fisher

Pacific Institute for Research and Evaluation

\section{Research}

Keywords: Alcohol-impaired driving, safety countermeasures, pilot cities, implementation, driving while intoxicated, injuries, fatalities, Columbus, Brasilia, Alexandra, Zacatecas

Posted Date: August 3rd, 2021

DOI: https://doi.org/10.21203/rs.3.rs-743896/v1

License: (9) This work is licensed under a Creative Commons Attribution 4.0 International License. Read Full License 


\section{Abstract}

\section{Background}

Beginning in 2016, the Anheuser-Busch InBev Foundation (ABIF) provided funding to six pilot cities to implement evidence-based interventions to reduce the harmful use of alcohol and its deleterious consequences such as alcohol-impaired driving. The cities receiving funding are Alexandra Township in Johannesburg, South Africa; Brasilia, Brazil; Columbus, Ohio, United States; Jiangshan, China; Leuven, Belgium; and Zacatecas, Mexico.

\section{Methods}

Four of the city pilot coalitions are implementing a wide array of interventions to deter driving under the influence (DUI). Columbus made efforts to get more judges to apply Ohio's alcohol ignition interlock law and implemented and evaluated a Safe Rides program. Brasilia increased the number of roadside checkpoints and planned an educational campaign about the dangers of impaired driving to be delivered at bars by firefighters and paramedics. Alexandra expanded and upgraded the Metropolitan Police Department's Alcohol Evidence Center (AEC). In Zacatecas, among other interventions, a new Driving While Intoxicated (DWI) facility is being constructed to expedite case processing and adjudication.

\section{Results}

In Columbus, the evaluation of the Safe Rides program showed an estimated reduction of 2.9 impaired driving crashes but also an average increase of 0.4 alcoholic drink per program participant. There was a reduction in harmful alcohol use of $.02 \%$ in 2017 associated with the Safe Rides campaign, but with no carryover to 2018. In Brasilia, the combined effect of the road safety measures and other factors resulted in a 35\% decrease in traffic deaths between 2016 and 2019. In Alexandra, there were 46 fatal crashes over the Easter weekend in 2018, 25 fatal crashes in 2019 (46\% reduction), and 3 fatal crashes in 2020 (88\% reduction from 2019). To date, Zacatecas' road safety measures have not yet been evaluated.

\section{Conclusions}

Full implementation of the city pilots' planned road safety interventions has been slow, and presently the COVID-19 pandemic has halted most operations. Interim evaluations can be conducted once a pilot city's countermeasures are fully implemented and have operated for at least one year. ABIF should continue to donate funds to increase or enhance evidence-based DUI enforcement strategies while also implementing awareness campaigns to inform the public and enhance the deterrent effect of those efforts.

\section{Contributions To The Literature}

- The Anheuser-Busch InBev Foundation (ABIF) was established to reduce the harms due to injurious alcohol consumption. Alcohol-impaired driving causes substantial morbidity and mortality across 
most countries of the world. ABIF is funding evidence-based countermeasures to reduce impaired driving in four pilot cities located in low and middle-income countries.

- Implementation of the selected countermeasures has progressed slowly. Presently, many activities have been temporarily halted or delayed by the COVID-19 pandemic.

- Researchers have identified a set of evidence-based countermeasures, and ABIF staff and outside consultants are continuing to advise the pilot cities on how to adapt and implement those interventions to suit local conditions and to plan for long-term sustainability. If these countermeasures prove to be effective, ABIF is poised to replicate those efforts in other cities around the world.

\section{Background}

Beginning in 2016, the Anheuser-Busch InBev Foundation (ABIF) provided funding to six city pilots to implement evidence-based interventions to reduce harmful drinking and its consequences by $10 \%$ by 2020. This effort was inspired by the United Nations' (UN) and the World Health Organization's (WHO) sustainable development goal (3.5.2) to reduce the harmful effects of alcohol globally by $10 \%$ by 2025 (WHO, 2018a). The cities receiving funding are Alexandra Township in Johannesburg, South Africa; Brasilia, Brazil; Columbus, Ohio, United States; Jiangshan, China; Leuven, Belgium; and Zacatecas, Mexico.

Each pilot city was provided funding to implement evidence-based countermeasures to reduce underage drinking, drinking by pregnant women, heavy episodic drinking, alcohol-related violence, and alcoholimpaired driving. This paper describes the ongoing implementation of road safety countermeasures in four of the city pilots: Alexandra, Brasilia, Columbus, and Zacatecas. Because of its focus on the city center, where there is very little automobile traffic, Leuven has not implemented any drink-driving countermeasures. The effort in Jiangshan never got underway due to the central government's unwillingness to grant ABIF permission to work in China.

In 2016, about 1.35 million people were killed in traffic crashes globally (WHO, 2018b). These fatalities, along with traffic-related injuries, take a significant human toll in terms of years of life and healthy life lost and have huge economic and social consequences. The first decade of this century has seen road safety receive greater attention from the international community than previous decades. In 2010 , the United Nations General Assembly proclaimed the years 2011 to 2020 as the "Decade of Action for Road Safety." The UN's focus on road safety was further strengthened by its adoption of two road safetyrelated Sustainable Development Goals: Target 3.6 calls for halving global deaths and injuries from road traffic crashes by 2020 , while Target 11.2 aims, by 2030 , to provide access to safe, affordable, and sustainable public transportation systems, with special attention paid to meeting the needs of vulnerable populations including pedestrians, women, children, persons with disabilities, and the elderly.

The major challenge in many countries is a lack of public awareness about the need for avoiding driving after drinking. Meeting this challenge requires institutional development; stricter laws and regulations, 
with more rigorous enforcement; reasonable penalties, to minimize the likelihood of police, prosecutors, and judges deciding not to charge or sanction offenders; and public communication campaigns to increase awareness of the problem, the measures being undertaken to reduce impaired driving, and the behavior changes people can adopt to avoid putting themselves and others at risk with regard to alcohol.

The city pilots will increase their chances of reducing alcohol-related crashes to the extent they adopt evidence-based policies and interventions that have proven successful in decreasing drink-driving. Random breath testing and roadside checkpoints need to be established as key enforcement strategies. Successful sanctions for drink-driving offences include license actions (Klein, 1989; Shults et al., 2001; Voas, Tippetts, \& Fell, 2000; Wagenaar, Zobeck, Hingson, \& Williams 1995; Zador, Lund, Field, \& Weinberg, 1988), appropriate fines (Wagenaar et al., 2007), and continuous transdermal monitoring to document reduced alcohol consumption (Dougherty et al., 2014). Requiring offenders to have an alcohol ignition interlock has been shown to reduce recidivism while also having a population-level deterrent effect (Willis et al., 2004; Teoh et al., 2018). Other alcohol policy strategies that have had modest effects on impaired driving include responsible beverage service (RBS) training and enforcing laws that prohibit serving alcohol to obviously intoxicated patrons (Holder \& Wagenaar, 1994; Toomey et al., 2001; Graham et al., 2004; Fell et al., 2017) and reducing or limiting alcohol outlet density (National Academies of Sciences, Engineering and Medicine, 2018).

Another challenge to addressing impaired driving is the scarcity of reliable and consistently collected data. In some of the city pilots, law enforcement and public health agencies have not developed a suitable data management system that could be utilized for policy analysis and evidence-based decisionmaking. Such data can be instrumental to identifying high-risk road users and locations with disproportionate crash involvement so that road safety measures can be implemented where needed most urgently and where they are likely to have the greatest effects.

An additional challenge stems from the substantial proportion of traffic fatalities in Alexandra, Zacatecas, and Brasilia among pedestrians, bicyclists, and motorbike riders, plus the fact that the percentage of those fatalities that are attributed to alcohol is unknown. In the United States, $34 \%$ of pedestrians killed in a collision with a motor vehicle had a blood alcohol concentration (BAC) greater than $.08 \mathrm{~g} / \mathrm{dL}$, while in the United Kingdom, $48 \%$ of pedestrian fatalities were drinking-related in the early 2000s (Stewart, 2004). Countermeasures for alcohol-impaired drivers are evident, but countermeasures for these other at-risk groups are underdeveloped.

The most effective and expedient strategy for reducing impaired driving is stricter DUI enforcement, coupled with awareness campaigns to inform the public about the higher enforcement levels and the sanctions and other costs that arrested DUI offenders will face (Voas, Rhodenizer, \& Lynn, 1985; Lacey, Rudisill, Popkin, \& Stewart, 1986; Epperlein, 1987; Homel, 1988; Levy, Shea, \& Asch, 1988; Levy, Asch, \& Shea, 1990; Wells, Preusser, \& Williams, 1992; Stuster and Blowers, 1995; Henstridge, Homel, \& Mackay, 1997; Miller, et al., 1998; Shults et al., 2001; Elder et al., 2002; Fell et al., 2004; Fell \& Voas, 2006; Voas, 2008). Frequent, visible, and publicized enforcement requires a substantial investment in manpower and 
equipment, plus the commitment of political leaders and law enforcement. ABIF's city pilots could make substantial progress if they used their limited resources to concentrate on this approach.

In this paper, we describe the road safety and impaired-driving countermeasures adopted, in progress, or planned by four of the city pilots.

\section{Methods}

Data were collected in two phases, a review of program documents and key informant surveys. Program documents and reports related to the road safety program were obtained from ABIF and reviewed to derive insights regarding goals and objectives, program design, and implementation arrangements. Documents from ABIF's evaluation contractor, HBSA, were also reviewed.

As a follow up, a key informant questionnaire was developed, pretested, and sent to key staff at the six city pilots. The questionnaire covered various aspects related to the road safety program, its results, and the impact of COVID-19 on planned activities. The responses were coded into themes and analyzed through thematic content analysis.

\section{Program Design And Implementation}

Alexandra, South Africa. An amendment to the Administrative Adjudication of Road Traffic Offenses Act (AARTO) calls for license suspension for drivers with two DUl offenses within 12 months. This new law is expected to change the driving behaviors of motorists who speed or drink and drive.

In 2019, ABIF funded an expansion and upgrade of the Alcohol Evidence Center (AEC) at the Metropolitan Police Department's Marlboro Testing Centre in order to improve post-arrest DUI processing. This is making it possible to implement roadside checkpoints, which often result in large numbers of DUI offenders being arrested.

In addition, the city pilot's coalition installed speed bumps on certain roads where pedestrian fatalities often occur. A comprehensive responsible beverage service (RBS) program is being planned which, in conjunction with increased enforcement of alcohol sales laws, may serve to reduce alcohol-related crashes and DUI arrests.

Brasilia, Brazil. Brasilia's city pilot coalition initiated several road safety countermeasures. The first was to increase the number of roadside checkpoints and to gather and analyze crash and DUI arrest data in order to relocate the checkpoints to critical areas. To deter drink-driving, the coalition used social media to publicize the checkpoints. There was also a planned initiative to revise the driver's license suspension protocol to make it more effective in dealing with DUI offenders.

On the engineering front, speed limits were decreased on specific roads in order to reduce vehiclepedestrian collisions. The coalition also started to reconfigure selected urban road intersections to make 
them safer for pedestrians and turning vehicles. Through a program called "Visible Pedestrian-Safe Pedestrian," homeless and elderly residents received reflective vests to increase their visibility in traffic.

The coalition planned an educational campaign to be delivered at bars by firefighters and paramedics with the Emergency Medical Rescue Service to underscore the dangers of impaired driving. This plan was suspended due to the COVID-19 pandemic but is currently being implemented. "Transit Guardians," an educational program for children about traffic-related dangers, was also halted because of the pandemic. Finally, the coalition formed a partnership with the food delivery app "Rappi" to promote motorcycle safety for Rappi workers.

Columbus, Ohio, USA. A BAC testing truck was purchased with ABIF funding to shorten the processing time for DUI offenders arrested by law enforcement. The BAC truck is deployed to the scene of a DUI arrest so that the arresting officer can return to patrolling sooner than is currently the case. DUI offenders were previously taken to police headquarters for processing which could take hours of the officer's time. However, given the city's size, police officers often have to wait for the truck to come on scene, which may sometimes undercut its efficacy in reducing officers' time spent on administrative aspects of enforcement. A social marketing campaign coinciding with the BAC truck's deployment was planned to make the public aware that DUI enforcement is increasing.

ABIF also supported efforts by MADD's Ohio state office to determine why so few adjudicated DUI offenders were being sentenced to use an alcohol ignition interlock. Ohio law states that offenders must ask for this sentencing option to be imposed, which only a few do, though some judges make clear that they expect offenders to make that request. The goal was to increase interlock sentencing from the current $6 \%$ of convicted DUI offenders up to $25 \%$.

A third measure was an experimental Safe Rides campaign implemented in 2017. Anheuser-Busch InBev provided coupons for a limited number of customers to get free rides with Lyft to and from the city's two main hospitality zones (bar and restaurant zones). Some alternative transportation programs have been shown to be effective (Fell et al., 2020).

Zacatecas, Mexico. Since 2016, the Zacatecas coalition has implemented several initiatives funded by ABIF. First, each year, ABIF has donated equipment to Road Safety Police Department (RSPD) to be used in roadside checkpoints in both Zacatecas and the neighboring city of Guadalupe, which is also part of the intervention site. Most recently, ABIF donated $\$ 350,000$ USD for construction of a new DWI facility to expedite case processing and adjudication, plus additional equipment for the roadside checkpoints. The facility is presently scheduled to open in the fall of 2021.

In 2019, the RSPD, with input from ABIF, modified the timing of its checkpoint operations. Previously, checkpoints were implemented only on Friday and Saturday evenings until 1:00 am on the main avenues. Checkpoints are now conducted every day at randomly selected times and locations, which is expected to be a more effective deterrence strategy, as has been the case with random breath testing in Australia (e.g., Homel, 1988). ABIF also helped organize and participated in a press conference to inform the public 
about the RSPD's plans for frequent roadside DUI checkpoints during the six-week holiday period starting in December 2019.

Importantly, the coalition also worked to bring about a change in the Internal Regulations of the Ministry of Public Security (Article 48, Section II) to establish the administrative arrest procedures for drivers arrested for DWI to avoid violations of their human rights and ensure compliance with the laws and regulations that govern police conduct.

There are three additional initiatives that may reduce alcohol-related crashes. First, with support from Grupo Modelo, an AB InBev company based in Zacatecas, the city mandated earlier closing times for both alcohol retail outlets $(10 \mathrm{pm})$ and on-premise establishments (2 am). Second, the Zacatecas coalition is planning a comprehensive RBS program focused on discouraging alcohol sales to minors under age 18, which may decrease alcohol-related crashes involving underage youth. Third, to kick off a new campaign, Grupo Modelo has purchased 20,000 subscriptions to the Druid ${ }^{\circledR}$ impairment app (Karoly et al., 2020 Richman \& May, 2019; Spindle et al., 2021) to be distributed free to the public, making it possible for people to develop the routine of checking their impairment level before deciding to drive or engage in other potentially risky activities. Starting in September 2021, the Zacatecas coalition will promote the app through the RBS program, RSPD's roadside checkpoints, its hospital-based alcohol screening program, and its social media platforms.

\section{Results}

Alexandra, South Africa. The COVID-19 pandemic seems to have reduced the number of fatal traffic crashes. In Gauteng Province, where Alexandra is located, there were 46 fatal crashes over Easter weekend in 2018; that figure decreased to 25 fatal crashes in 2019 (46\% reduction) and to 3 fatal crashes over Easter weekend in 2020 during the COVID-19 lockdown (88\% reduction from 2019).

In response to COVID-19, the South African government ordered a lockdown and a ban on alcohol sales on March 27, 2020. According to the South African Medical Research Council (SAMRC), the number of weekly deaths in South Africa declined from 8,606 during the week of January 1,2020, to 7,115 during the week of March 25, 2020, and 7,135 during the week of April 22, 2020. These numbers include COVID19 deaths. Health experts have attributed the decrease to the alcohol sales ban and reduced vehicle use during the lockdown. The SAMRC estimated there have been more than 5,000 fewer weekly admissions to trauma centers due to the alcohol ban (Mogotsi and Bearak, 2020).

Brasilia, Brazil. The combined effects of Brasilia's road safety initiatives produced a sizeable decrease in traffic deaths in the city's Ceilandia and Taguatinga districts between 2016 and 2019 (see Table 1). The impact of the pandemic is not yet known. 
Table 1

Traffic Fatalities in Brasilia

\begin{tabular}{|lllll|}
\hline Year & $\mathbf{2 0 1 6}$ & $\mathbf{2 0 1 7}$ & $\mathbf{2 0 1 8}$ & $\mathbf{2 0 1 9}$ \\
\hline Traffic Fatalities & 63 & 39 & 57 & 41 \\
\hline \% Change, & & & & $-35 \%$ \\
2016 to 2019 & & & & \\
\hline Source: Falconi & & & & \\
\hline
\end{tabular}

Columbus, Ohio, USA. In Columbus, the evaluation of the Safe Rides program showed an estimated reduction of 2.9 impaired driving crashes but also an average increase of 0.4 alcoholic drink per program participant. There was an estimated reduction in harmful alcohol use of .02\% in 2017 associated with the Safe Rides campaign, with no carryover to 2018 (Miller et al., 2020).

As shown in Table 2, with the stay-at-home order issued as a result of COVID-19, the pandemic had dramatically reduced motor vehicle crashes in Columbus in the beginning of 2020 .

Table 2

Motor Vehicle Crashes in Columbus

\begin{tabular}{|lll|}
\hline Time Period & Total Reported Crashes & Alcohol-Related Crashes \\
\hline $3 / 1-3 / 31 / 2018$ & 1876 & 80 \\
\hline $3 / 1-3 / 31 / 2019$ & 1906 & 76 \\
\hline $3 / 1-3 / 31 / 2020$ & 1120 & 48 \\
\hline$\%$ Change & $-41 \%$ & $-37 \%$ \\
2019 to 2020 & & \\
\hline Source: Columbus Police Department & \\
\hline
\end{tabular}

Zacatecas, Mexico. A formal evaluation of the city's road safety countermeasures has not been completed, but data forwarded by ABIF staff in Zacatecas show that impaired-driving fatalities increased in the cities of Zacatecas and Guadalupe in 2020 (see Table 3). Further investigation is needed to understand why this has occurred. One possibility is that investigating police are now more focused on determining whether traffic fatalities are due to alcohol-impaired driving. 
Table 3

Zacatecas/Guadalupe Impaired-Driving

Fatalities

\begin{tabular}{|ll|}
\hline Year & Number of Fatalities in January-April \\
\hline 2018 & 33 \\
\hline 2019 & 40 \\
\hline 2020 & 60 \\
\hline Source: Road Safety Police Department \\
\hline
\end{tabular}

\section{Discussion}

Preliminary trends in the outcomes of the impaired driving countermeasures are promising in three of the four pilot cities. Comprehensive evaluations using regression analyses will inform ABIF officials as to which countermeasures are more effective than others. Funding can then be targeted to the most efficacious countermeasures for replication in other cities. Although reducing the overall harmful effects of alcohol by $10 \%$ by 2025 may be difficult to accomplish in these the pilot cities, reducing impaired driving crashes, injuries, and fatalities by $10 \%$ by 2025 is achievable if all the countermeasures are implemented properly.

There are a number of limitations to this descriptive study. (1) There is currently not enough data nor a long enough time period at the pilot city sites to conduct more formal evaluations. The COVID-19 pandemic shut down operations for over a year so it will take longer to collect the appropriate data. (2) While this was a descriptive study of the countermeasures implemented in the four pilot cities, detailed descriptions of how the countermeasures were implemented were not available. (3) Certain desirable data such as arrests for driving while intoxicated (DWI) and blood alcohol concentrations of drivers involved in crashes were not available in the four pilot cities.

\section{Conclusions}

Full implementation of the pilot cities' planned road safety interventions has been slow, and presently the COVID-19 pandemic halted most operations during 2020 and early 2021. Miller and Ringwalt (2019) estimated the baseline level of alcohol-related harms in all six pilot cities. Thus, interim evaluations can be conducted when a city's road safety countermeasures are fully implemented and have operated for at least one year. These evaluations will need to account for the COVID-19 pandemic's impact on traffic volume. As noted above, the pandemic has substantially reduced travel and the number of fatal crashes in many countries and communities (e.g., Shilling \& Waetjen, 2020).

Most of the city pilots have been following the five-step framework for implementing road safety countermeasures (see Table 4). ABIF staff and outside consultants are continuing to advise the pilot cities on how to adapt and implement those interventions to suit local conditions and to plan for long- 
term sustainability. If these countermeasures prove to be effective, ABIF is poised to replicate those efforts in other cities around the world. 
Table 4

Five-step Framework for Implementing Road Safety Countermeasures

\section{Step 1: Identify the Problem}

What proportions of traffic fatalities involve alcohol?

What proportion of drivers in fatal crashes have BACs over the limit?

What proportion of fatally injured pedestrians have alcohol?

What proportion of fatally injured bicyclists have alcohol?

What proportion of motor scooter/motorcycle riders have alcohol?

\section{Step 2: Assemble a Leadership Team}

Get support from at least one political leader

President, Governor, Prime Minister, Mayor, etc.

Include motivated/interested stakeholders.

Invite legislators, law enforcement, prosecution, judiciary, probation, treatment providers, driver licensing agency, hospitality/alcohol industry, etc.

Select a Coordinator

\section{Step 3: Develop a Strategic Plan}

Public Information and Education

Legislation

Enforcement

Prosecution

Judicial

Treatment

Medical Community

Alternative Transportation

Public transportation, rideshare service; designated driver; sober ride)

\section{Step 4: Implement the Plan}

Monitor progress

Make midcourse adjustments as needed

Conduct a formal process evaluation

Step 5: Evaluate the Interventions' Effectiveness 


\section{Step 1: Identify the Problem}

Reduction in alcohol-related fatalities

Changes in other outcome measures

Discuss lessons learned

Plan revisions and implement

Moving forward, the city pilot coalitions should provide information to lawmakers and regulators about additional laws, regulations, and evidence-based countermeasures for deterring impaired driving. ABIF should continue to donate funds to increase or enhance DUI enforcement strategies while also implementing awareness campaigns to inform the public and enhance the deterrent effect of those efforts.

\section{Abbreviations}

ABIF

Anheuser-Busch InBev Foundation;

DUI

Driving under the influence;

AARTO

Administrative Adjudication of Road Traffic Offenses Act

AEC

Alcohol Evidence Center

DWI

Driving while intoxicated

WHO

World Health Organization

UN

United Nations

RBS

Responsible Beverage Service

BAC

Blood Alcohol Concentration

MADD

Mothers Against Drunk Driving

RSPD

Road Safety Police Department

SAMRC

South African Medical Research Council 


\section{Declarations}

Ethics Approval - Not applicable

Consent for Publication - Not applicable

Availability of Data - The data that support the findings from this study were analyzed and summarized by the implementation staffs of each pilot city.

Competing Interests - The authors do not have any competing interests.

Funding - Funding for the work on this manuscript was provided by the $A B \operatorname{InBev}$ Foundation (ABIF).

Authors' Contributions - JF was lead author and wrote most of the manuscript. TA obtained information on all of the countermeasures implemented in the pilot cities and edited the final draft. WD provided some of the evaluation data and edited the manuscript. DF provided much of the trend data and data analysis from the pilot cities and reviewed and edited various drafts of the manuscript.

Acknowledgements - The authors wish to thank Catalina Garcia from ABIF for her leadership and encouragement in summarizing these implementation measures.

\section{References}

Dougherty DM, Hill-Kapturczak N, Liang Y, Karns TE, Cates SE, Lake SL, Mullen J, Roache JD. Use of continuous transdermal alcohol monitoring during a contingency management procedure to reduce excessive alcohol use. Drug Alcohol Depend. 2014;142:301-6.

Elder RW, Shults RA, Sleet DA, Nichols JL, Zaza S, Thompson RS. Effectiveness of sobriety checkpoints for reducing alcohol-involved crashes. Traffic Injury Prevention. 2002;3:266-74.

Epperlein T. Initial deterrent effects of the crackdown on drunken drivers in the state of Arizona. Accid Anal Prev. 1987;19:271-83.

Fell JC, Voas RB. Mothers Against Drunk Driving (MADD): The first 25 years. Traffic Injury Prevention. 2006;7:195-212.

Fell JC, Waehrer G, Voas RB, Auld-Owens A, Carr K, Pell K. Effects of enforcement intensity on alcohol impaired driving crashes. Accid Anal Prev. 2014;73:181-6.

Fell JC, Fisher DA, Yao J, McKnight AS. Evaluation of a responsible beverage service and enforcement program: Effects on bar patron intoxication and potential impaired driving by young adults. Traffic Injury Prevention. 2017;18:557-65. 
Fell JC, Scolese J, Achoki T, Burks C, Goldberg A, DeJong W. The effectiveness of alternative transportation programs in reducing impaired driving: A literature review and synthesis. J Saf Res. 2020;75:128-39. https://doi.org/10.1016/j.jsr.2020.09.001.

Graham K, Osgood DW, Zibrowski E, Purcell J, Gilksman L, Leonard K,... Toomey TL. The effect of the safer bars programme on physical aggression in bars: Results of a randomized controlled trial. Drug Alcohol Rev. 2004;23:31-41.

Henstridge J, Homel R, Mackay P. The Long-term Effects of Random Breath Testing in Four Australian States: A Time Series Analysis. Canberra: Federal Office of Road Safety; 1997.

Holder HD, Wagenaar AC. Mandated server training and reduced alcohol-involved traffic crashes: A time series analysis of the Oregon experience. Accident Analysis Prevention. 1994;26:89-97.

Homel R. Policing and Punishing the Drinking Driver. A Study of General and Specific Deterrence. New York: Springer-Verlag; 1988.

Klein TM. Changes in Alcohol-involved Fatal Crashes Associated with Tougher State Alcohol Legislation (DOT-HS-807-551). 1989, Washington, DC: National Highway Traffic Safety Administration, U.S. Department of Transportation.

Karoly HC, Milburn MA, Brooks-Russell A, Brown M,... Bidwell LC. Effects of high potency cannabis on psychomotor performance in frequent cannabis users. Cannabis Cannabinoid Research. 2020. [DOI: 10.1089/can.2020.0048].

Lacey JH, Rudisill LC, Popkin CL, Stewart JR. (1986). Education for drunk drivers: How well has it worked in North Carolina? Popular Government, 1986, 51(3), 44-48.

Levy D, Shea D, Asch P. Traffic safety effects of sobriety checkpoints and other local DWI programs in New Jersey. Am J Public Health. 1988;79:291-3.

Levy D, Asch P, Shea D. An assessment of county programs to reduce driving while intoxicated. Health Educ Res. 1990;5:247-55.

Miller T, Courser M, Shamblen S. The Efficacy of Ride-Sharing Services in Reducing Drinking and Related Harms in Columbus, OH. Calverton: HBSA; 2020.

Miller T, Ringwalt C. Anticipated Reductions in Harmful Use of Alcohol from Planned Activities in Six Cities. Calverton: HBSA; 2019.

Miller TR, Galbraith M, Lawrence BA. Costs and benefits of a community sobriety checkpoint program. J Stud Alcohol. 1998;59:465-8. 
Mogotsi B, Bearak M Deaths down, ire up during South Africa's lockdown alcohol ban. Washington Post, Sunday, May 10, 2020, p-A21.

National Academies of Sciences, Engineering and Medicine. Getting to zero alcohol- impaired driving fatalities: A comprehensive approach to a persistent problem. Washington, DC: The National Academies Press, 2018.

Richman JE, May S. An investigation of the Druid ${ }^{\circledR}$ smartphone/tablet app as a rapid screening assessment for cognitive and psychomotor impairment associated with alcohol intoxication. Vision Development Rehabilitation. 2019;5:31-42. [DOI: 10.31707/VDR2019.5.1].

Shilling F, Waetjen D. Special Report: Impact of COVID-19 on California Traffic Accidents. Road Ecology Center, University of California, Davis. 4/1/2020. https://roadecology.ucdavis.edu.

Shults RA, Elder RW, Sleet DA, Nichols JL, Alao MO, Carande-Kulis VG,.. . Thompson RS. Reviews of evidence regarding interventions to reduce alcohol- impaired driving. Am J Prev Med. 2001;21(4 Suppl):66-88.

Spindle TR, Martin E, Grabenauer M, Woodward T, Milburn M, Vandrey R. Assessment of cognitive and psychomotor impairment, subjective drug effects, and blood THC concentrations following acute administration of oral and vaporized cannabis. Journal of Psychopharmacology, 2021. 02698811211021583.

Stewart K. Alcohol Involvement in Fatal Crashes: Comparisons among Countries (DOT-HS-809-355). Washington, DC: National Highway Traffic Safety Administration: U.S. Department of Transportation; 2004.

Stuster JW, Blowers MA. Experimental Evaluation of Sobriety Checkpoint Programs (D0T-HS-808-287). Washington, DC: National Highway Safety Administration, U.S. Department of Transportation; 1995.

Teoh ER, Fell JC, Scherer M, Wolfe DE. State Alcohol Ignition Interlock Laws and Fatal Crashes. Arlington: Insurance Institute for Highway Safety; 2018.

Toomey TL, Wagenaar AC, Gehan JP, Kilian G, Murray DM, Perry CL. Project ARM: alcohol risk management to prevent sales to underage and intoxicated patrons. Health Education Behavior. 2001;28:186-99.

Voas RB, Rhodenizer AE, Lynn C. Evaluation of Charlottesville Checkpoint Operations (DOT-HS-806-989). Washington, DC: National Highway Traffic Safety Administration, U.S. Department of Transportation; 1985.

Voas RB. A new look at NHTSA's evaluation of the 1984 Charlottesville Sobriety Checkpoint Program: Implications for current checkpoint Issues. Traffic Injury Prevention. 2008;9:22-30. 
Voas RB, Tippetts AS, Fell JC. The relationship of alcohol safety laws to drinking drivers in fatal crashes. Accid Anal Prev. 2000;32:483-92.

Wagenaar AC, Zobeck TS, Hingson R, Williams GD. Studies of control efforts: A meta-analysis from 1960 through 1991. Accid Anal Prev. 1995;27:1-16.

Wagenaar AC, Maldonado-Molina MM, Erickson DJ, Ma L, Tobler AL, Komro KA. General deterrence effects of U.S. statutory DUI fine and jail penalties: Long-term follow-up in 32 states. Accid Anal Prev. 2007;39:982-94.

Wells JK, Preusser DF, Williams AF. Enforcing alcohol-impaired driving and seat belt use laws, Binghamton, New York. J Saf Res. 1992;23:63-71.

Willis C, Lybrand S, Bellamy N. Alcohol ignition interlock programmes for reducing drink driving recidivism. Cochrane Database of Systematic Reviews. 2004;18(4):CD004168.

World Health Organization (WHO). Global Status Report on Alcohol and Health 2018. Geneva: Licence: CC BY-NC-SA 3.0 IGO, 2018a.

World Health Organization (WHO). Global Status Report on Road Safety 2018. Geneva: Licence: CC BYNC-SA 3.0 IGO, 2018b.

Zador PK, Lund AK, Field M, Weinberg K. Alcohol-impaired Driving Laws and Fatal Crash Involvement. Washington, DC: Insurance Institute for Highway Safety; 1998. 